\title{
Thalidomide in refractory bleeding due to gastrointestinal angiodysplasias
}

\author{
Antonio Garrido, Manuel Sayago, Jaime López, Rafael León, Francisco Bellido and Jose Luis Márquez \\ Department of Digestive Diseases. Hospital Universitario Virgen del Rocío. Sevilla, Spain
}

\begin{abstract}
Objectives: to assess the efficacy of thalidomide in the treatment of relapsed or refractory bleeding secondary to gastrointestinal angiodysplasia.

Material and methods: we carried out a prospective study of 12 patients with bleeding due to gastrointestinal angiodysplasia refractory to conventional therapy who were treated with thalidomide. For each patient, we considered: age, sex, underlying disease, previous therapies, dose and duration of thalidomide treatment, evolution of haemoglobin levels and adverse effects of treatment. The data obtained were analysed using descriptive statistics with SPSS v. 16.

Results: seven men and 5 women with a mean age of 77 years were included in the present study. Five had some underlying pathology and all of them had received prior endoscopic/octreotide treatment. The dose of thalidomide administered was $200 \mathrm{mg} / 24 \mathrm{~h}$ and the duration of the treatment four months, with the exception of two patients in whom treatment was discontinued because of adverse side effects. Mean haemoglobin concentration before onset of treatment was $6.5 \mathrm{~g} / \mathrm{dL}$, at two months it was $11.3 \mathrm{~g} / \mathrm{dL}$ and at the end of treatment $12.1 \mathrm{~g} / \mathrm{dL}$.

Conclusions: thalidomide is an effective treatment in gastrointestinal bleeding due to angiodysplasia, but it was withdrawn due to side effects in $16 \%$ of the patients included in our study.
\end{abstract}

Key words: Gastrointestinal bleeding. Angiodysplasia. Thalidomide. Vascular malformations.

Garrido A, Sayago M, López J, León R, Bellido F, Márquez JL. Thalidomide in refractory bleeding due to gastrointestinal angiodysplasias. Rev Esp Enferm Dig 2012; 104: 69-71.

Received: 26-09-11

Accepted: 18-10-11

Correspondence: : Antonio Garrido. Department of Digestive Diseases. Hospital Universitario Virgen del Rocío. Avda. Manuel Siurot, s/n. 41013. Sevilla, Spain.

e-mail: agarser@telefonica.net

\section{INTRODUCTION}

Gastrointestinal bleeding and chronic ferropenic anaemia resulting from vascular lesions of the digestive tract sometimes pose a difficult therapeutic challenge due to the location and multiplicity of such lesions. This causes the deterioration in the quality of life of patients and a significant use of sanitary resources (1). The presence of high levels of vascular endothelial growth factor (VEGF) promotes aberrant angiogenesis and formation of angiodysplasias with a vascular endothelium lacking in smooth muscle cells and therefore prone to ruptures. Thalidomide is a drug with a potent anti angiogenic effect which inhibits VEGF and reduces its level significantly (1).

So far, few reports have been published of clinical cases showing the efficacy of thalidomide in the treatment of gastrointestinal bleeding due to angiodysplasias $(1,2)$ or severe proctitis following radiotherapy (3). In the present study, we report a series of patients with gastrointestinal bleeding and disabling anaemia syndrome due to gastrointestinal dysplasias refractory to endoscopic and/or octreotide treatment and who were administered thalidomide.

\section{MATERIAL AND METHODS}

We carried out a prospective study of a series of multitransfused patients with gastrointestinal bleeding and severe ferropenic anaemia who did not respond to endoscopic argon plasma coagulation treatment or somatostatin analogue therapy. All patients were informed about thalidomide treatment and gave their informed consent to take part in the study. We excluded from the study female patients in fertile age, patients with active infection at the onset of therapy and patients with hepatic cirrhosis as underlying pathology.

For each patient, we considered the following parameters: age, sex, underlying pathology, previous therapies, dose and 
duration of thalidomide treatment, evolution of haemoglobin concentration during treatment and transfusions required as well as adverse side effects of the treatment.

The diagnosis of gastrointestinal angiodysplasias was obtained through upper and lower gastrointestinal endoscopy. Angiodysplasia of the small intestine was diagnosed by means of video capsule endoscopy (with push enteroscopy or double-balloon enteroscopy in case of therapy).

\section{RESULTS}

We included in our study 12 patients, 7 males and 5 females, with a mean age of $77 \mathrm{yrs}$; all of them had received multiple transfusions and had been admitted on several occasions due to gastrointestinal bleeding and anaemia and all of them had received endoscopic and/or drug therapy with octreotide but had not responded favourably. Table I shows the general characteristics of the patients.

The dose of thalidomide administered was $200 \mathrm{mg} / 24 \mathrm{~h}$ and the estimated initial duration of treatment was 4 months for all patients. However, the treatment was discontinued after 3 days in one patient due to gastrointestinal intolerance to the drug and after one week in another patient due to fever and thrombophlebitis after cat scratching. Figure 2 shows the evolution of haemoglobin concentration two months after onset of therapy in which we can observe a significant increase which continues until end of therapy. Another patient showed signs compatible with axonal sensitive polyneuropathy which prompted withdrawal of thalidomide. The symptoms resolved once the treatment had finished. None of the patients required transfusions during the study period.

\section{DISCUSSION}

Thalidomide shows anti-inflammatory, immunomodulatory and anti-angiogenic properties and inhibits VEGF production, which is considered a key factor for the formation of the vascular endothelium in the initial stages of angiogenesis.

Thalidomide is a recent and promising therapeutic option in patients with gastrointestinal bleeding and anaemia secondary to vascular malformations. According to the literature, it is administered orally at variable doses, which range from 100 to $300 \mathrm{mg} /$ day and for a period between 1 and 6 months (1-3).

Thalidomide is contraindicated in the case of patients with peripheral neuropathy, in pregnant women due to its teratogenic effects and in patients with active infections due to its immunosuppressive property and its ability to inhibit of tumour necrosis factor alpha. It must be used with caution in patients with renal, cardiovascular or liver diseases, as severe cases of hepatotoxicity have been reported in the literature (4).
Table I. General characteristics of the patients included in our sample $(n=12)$

\begin{tabular}{|c|c|c|c|c|c|c|c|}
\hline Patient & $\begin{array}{l}\text { Age } \\
\text { (years) }\end{array}$ & Sex & $\begin{array}{l}\text { Underlying } \\
\text { diseas }\end{array}$ & $\begin{array}{l}\text { AGD } \\
\text { location }\end{array}$ & $\mathrm{HbO}$ & $\mathrm{Hb} 2$ & Hb4 \\
\hline 1 & 74 & M & No & $I D+C$ & 5.8 & 10.4 & 12.2 \\
\hline 2 & 79 & M & $\begin{array}{l}\text { Heart } \\
\text { failure }\end{array}$ & $I D+C$ & 7.2 & & \\
\hline 3 & 83 & M & $\begin{array}{l}\text { Heart } \\
\text { failure }\end{array}$ & ID & 6.9 & 11.6 & 11.9 \\
\hline 4 & 72 & $\mathrm{~F}$ & No & $I D+C$ & 6.3 & & \\
\hline 5 & 75 & $\mathrm{~F}$ & No & C & 7.0 & 12.1 & 13.0 \\
\hline 6 & 80 & $M$ & IRC & $I D+C$ & 7.3 & 13.0 & 12.9 \\
\hline 7 & 69 & $\mathrm{~F}$ & No & C & 7.0 & 12.5 & 12.7 \\
\hline 8 & 84 & M & No & ID & 6.1 & 0.6 & 11.9 \\
\hline 9 & 75 & $\mathrm{~F}$ & No & ID & 6.4 & 11.0 & 12.5 \\
\hline 10 & 79 & $\mathrm{~F}$ & Valvulopathy & $G+I D$ & 6.3 & 10.8 & 11.4 \\
\hline 11 & 68 & M & No & $I D+C$ & 6.7 & 11.5 & 12.8 \\
\hline 12 & 86 & M & $\begin{array}{l}\text { Heart } \\
\text { failure }\end{array}$ & $G+I D+C$ & 5.0 & 8.5 & 9.7 \\
\hline
\end{tabular}

AGD: angiodysplasia. HbO: baseline haemoblobin. Hb2: haemoglobin at two months. Hb4: final haemoglobin level. G: stomach. SB: small bowel. C: colon. CRF: chronic renal failure.

Endoscopic capsule examination shows a reduction in the number, size and colour of vascular lesions in patients receiving thalidomide treatment, and control of haemorrhage during a mean follow up period of 2-3 years without necessity of transfusions. In general, the adverse side effects reported in the literature are not severe (fatigue, peripheral neuropathy, skin rash) and resolved after withdrawal of the drug. Moreover, as thalidomide acts in the origin of these lesions through VEGF inhibition, it prevents the development of future angiodysplasias (5).

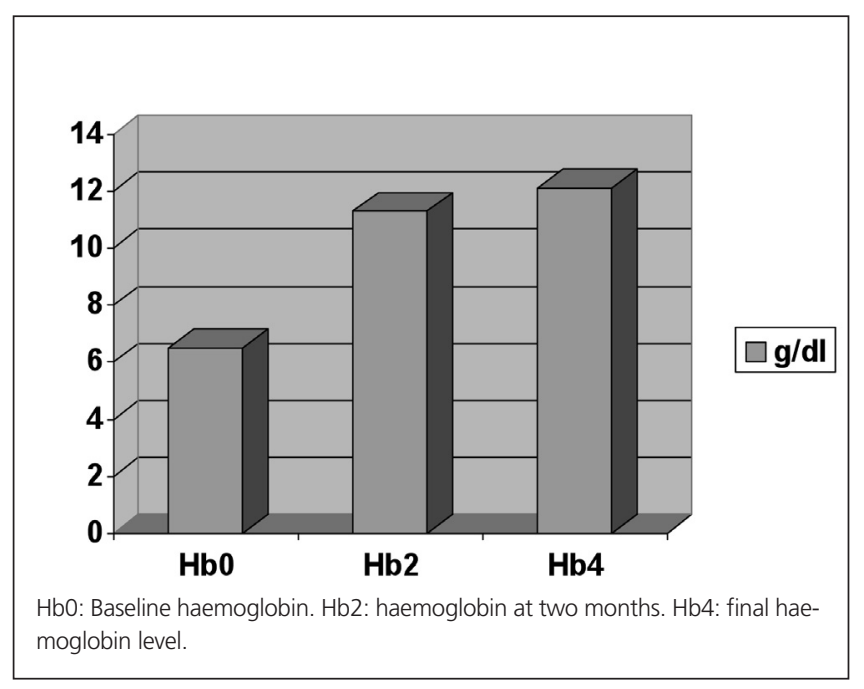

Fig. 1. Evolution of haemoglobin levels throughout the treatment period. 
So far, few reports have assessed the efficacy of thalidomide in the treatment of gastrointestinal bleeding due to angiodysplasia with the exception of a few isolated cases $(6,7)$, being our series of patients the largest reported in the medical literature.

Thalidomide has also proved to be effective in the management of refractory bleeding due to gastropathy in patients with portal hypertension (8), severe postradiotherapy proctitis (3) and has also been satisfactorily employed in a patient with Von Willebrand disease and bleeding due to small bowel angiodysplasia who had not responded to previous treatment with tranexamic acid, desmopressin, octreotide, recombinant factor VII and endoscopic argon plasma coagulation (9).

It has been demonstrated that VEGF inhibition depends on the dose of thalidomide administered (1). In the present study, patients received a single dose of $200 \mathrm{mg} /$ day which proved highly effective and had few and scarcely relevant side effects. The increase in haemoglobin levels, up to $5 \mathrm{~g} / \mathrm{dL}$ higher at the end of the treatment, has made it possible to control the symptoms typical of the anaemia syndrome, to reduce the necessity of transfusions, hospital admissions, and complementary tests, many of them in the form of digestive endoscopy. As a result, the quality of life of patients improves and discomfort diminishes. Although there is no study published on the analysis of costs, undoubtedly the above mentioned factors also entail significant economic saving.

Several points must still be clarified: one of the most important, in our opinion, is the optimum duration of treatment. According to the results of our study, the maximum haemoglobin level is reached approximately two months after onset of treatment, although the last two months may contribute to the complete elimination of angiodysplasias. Optimum dose, comparison of thalidomide treatment with somatostatin analogue therapy, endoscopic treatment, etc. are other issues to consider.
In view of the results obtained, we think it will be necessary to reconsider the role thalidomide plays in the treatment of this type of lesions. At present it is used as thirdor fourth-line treatment applied to refractory lesions (10). Due to the small samples included in the reports published in the scientific literature on this subject, it will probably be necessary to carry out multicentric studies to clear all these doubts and definitely establish thalidomide as a new and promising therapeutic option for these patients (11).

\section{REFERENCES}

1. Ge ZZ, Chen HM, Gao YJ, Liu WZ, Xu CH, Tan HH et al. Efficacy of thalidomide for refractory gastrointestinal bleeding from vascular malformations. Gastroenterology 2011;141:1629-37.

2. Kamalaporn P, Saravanan R, Cirocco M, May G, Kortau P, Candel G. Thalidomide for the treatment of chronic gastrointestinal bleeding from angiodysplasias: a case series. Eur J Gastroenterol Hepatol 2009;21:1347-50.

3. Craanen ME, van Triest B, Verjeihen RH, Mulder CJ. Thalidomide in refractory haemorrhagic radiation induced proctitis. Gut 2006;55:1371-2.

4. Hanje A, Shamp JL, Thomas FB, Meis GM. Thalidomide-induced severe hepatotoxicity. Pharmacotherapy 2006;26:1018-22.

5. Bauditz J, Lochs H, Voderholzer W. Macroscopic appearance of intestinal angiodysplasias under antiangiogenic treatment with thalidomide. Endoscopy 2006;38:1036-9.

6. Serralta D, Arjona I, García A, Sanz M, Turégano F. Hemorragia invalidante y recidivante por angiodisplasia intestinal: tratamiento con talidomida. Rev Esp Enferm Dig 2008;100:306-7.

7. Fernández LI, Velayos B, Fernández I, Aller R, González JM. Eficacia de la talidomida en la hemorragia digestiva por angiodisplasias. Rev Esp Enferm Dig 2009:101:371.

8. Karajeh MA, Hursltone DP, Stephenson TJ, Ray-Chaudhuri D, Gleeson DC. Refractory bleeding from portal hypertensive gastropathy: A further novel role for thalidomide therapy? Eur J Gastroenterol Hepatol 2006;18:545-8.

9. Hirri HM, Green PJ, Lindsay J. Von Willebrand's disease and angiodysplasia treated with thalidomide. Haemophilia 2006;12:285-6.

10. Molina-Infante J, Pérez-Gallardo B. Somatostatin analogues for bleeding gastrointestinal angiodysplasias: when should thalidomide be prescribed? Dig Dis Sci 2011;56:266-7.

11. Molina-Infante J, Pérez-Gallardo B, Fernández-Bermejo M. Avances en el tratamiento farmacológico de la hemorragia digestiva de origen oscuro. Rev Esp Enferm Dig 2007;99:457-62. 